\title{
Selection of the optimal type of thermal insulation structure based on the neural network modelling
}

\author{
Irina Akhmetova ${ }^{1, *}$, Elena Balzamova ${ }^{1}$, Veronika Bronskaya $^{2}$, Denis Balzamov ${ }^{1}$, Konstantin Lapin ${ }^{3}$ and $O l g a$ Kharitonova $^{2}$ \\ ${ }^{1}$ Kazan State Power Engineering University, 420066, 51 Krasnoselskaya Street, Kazan, Russian Federation \\ ${ }^{2}$ Kazan National Research Technological University, 420015, 68 Karl Marx Street, Kazan, Russian Federation \\ ${ }^{3}$ JSC «Tatenergo», Kazan, Russian Federation
}

\begin{abstract}
A software package with the user interface for calculating, analyzing and predicting the parameters of cogeneration-based district heating based on the neural network modelling is presented in order to optimize and ensure the reliability of heat networks. The package is the basis for a web-application that allows to calculate the characteristics of the heat network in accordance with the model, keep a query log and provide the possibility of administration.
\end{abstract}

\section{Introduction}

When designing a thermal insulation structure, the question came up about the range of applicability of various sealing materials depending on the curvature of the surface on which they are installed, so it is important: - to select the optimal thermal insulation materials - to calculate the thickness of the thermal insulation layer to ensure acceptable heat loss;

- to select the standard sizes of thermal insulation materials[1-6]

\section{Package of control and forecast of optimal thickness of thermal insulation}

In order to create a complex for monitoring and predicting the optimal thermal insulation, a neural network model of the selection of thermal insulation material and a Windows Forms application were created.

The multi-layer direct distribution network is used in the course of the work. The training procedure requires typing the input and output data from the process. During training, weights and offsets are iteratively adjusted to minimize the objective function. The learning algorithm (backpropagation) transfers the network parameters in the direction of a negative gradient. The activation function is sigmoid with a coefficient equal to 1 .

Initially, it is important to define the input and output variables. Based on the goals and objectives, the input and output data are presented in table 1 .
Table 1. Input and output parameters of the neural network

\begin{tabular}{|c|c|}
\hline Input & Output \\
\hline $\begin{array}{c}\text { Thermal } \\
\text { conductivity coefficient }\end{array}$ & $\begin{array}{c}\text { The thickness of the } \\
\text { thermal insulation }\end{array}$ \\
\cline { 1 - 1 } Density & \\
\hline
\end{tabular}

Then the architecture of the artificial neural network should be selected. Figure 1 shows the neural network diagram.

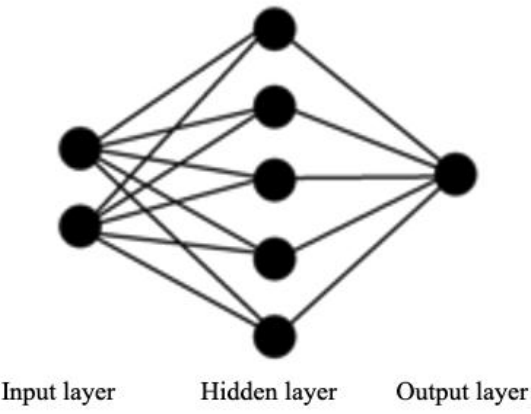

Fig. 1. The topology of the neural network.

In the course of this work, a Windows Forms application was created. A user can independently maintain a database of insulation materials: to add new materials to it and edit the parameters of existing ones, such as insulation structures and products made of mineral wool, K-Flex, Rockwool, Foam-GLAS[7,8] .

The main task of the developed system is to calculate the thickness of the thermal insulation based on the entered coefficient of thermal conductivity and density. Thus, the program will provide a forecast of the thickness of the thermal insulation, taking into account the minimization of heat losses.

* Corresponding author: e.balzamova@mail.ru 
The system is the web-application that allows to calculate the characteristics in accordance with the neural network model and keep the query log of users.

The main stages of the software package operation:

1. After authorization, the user opens the main page of the program.

2. After clicking on the "Calculate values" button, the system checks the correctness of data entry directly on the client side and, if successful, transmits the data to the server.

3. After successful calculation, the output characteristics of the synthesis are displayed in the results window in the formatted form.

4. If it is important to vary one or more output characteristics, the user changes the input data and requires the recalculation. It is important to note that if a user sets up the input parameters that they or another user typed earlier, the calculation will occur almost without time delays since in this case the query results are already stored in the system.

5. A special request $\log$ is kept for each user of the system. In this section, the user can see their latest queries with the date and time and their results.

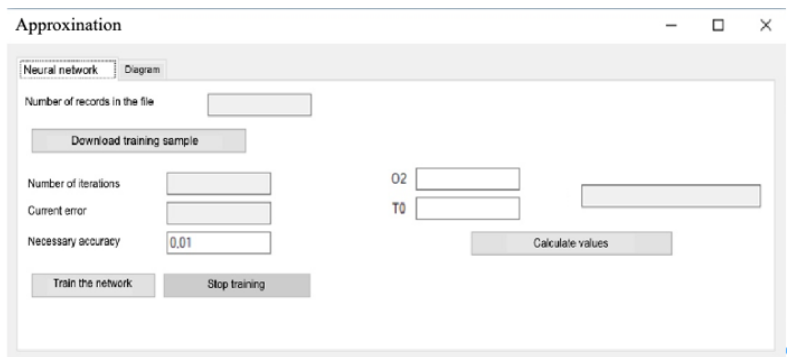

Fig. 2. The application interface for working with the neural network.

Loading input data from a file for training the neural network was implemented. The CSV format was chosen for files for ease of writing and reading.

The adequacy test was performed using the coefficient of determination. According to the values of R2 when checking the network for adequacy, the value of the determination coefficient in the case of training (0.99811) and testing (0.99222) samples are close on average and there is no network retraining.

\section{Conclution}

The web-application has been developed for predicting optimal thermal insulation using the artificial neural network. Training and test samples of the network were created based on the experimental data and responses from the neural network were obtained. Thus, a neuromodel of the relationship between technological factors and optimal thermal insulation is built as the basis of the web-application using multi-layer neural networks.

\section{References}

1. D.S. Balzamov, I.G. Akhmetova, E.Y. Balzamova, G.I. Oykina, V.V. Bronsrkaya Options for organizing own sources of energy supply at the facilities of generating companies based on steam screw machines, Journal of Physics: Conference Series, 1399, 055018 (2019)

2. D.S. Balzamov, E.Y. Balzamova, S.R. Ibatullin, L.S. Sabitov Efficiency increase of gas turbine work in the summer period, IOP Conference Series: Materials Science and Engineering, 570, 012008 (2019)

3. D.S. Balzamov, L.S. Sabitov, B.F. Timershin, E.Yu. Balzamova Evaluation of the applicability of pre-evaporative cooling of air in front of the cooling tower in the conditions of the third climatic zone of the Russian Federation, IOP Conference Series: Materials Science and Engineering, 412, 012006 (2018)

4. D.S. Balzamov, L.S. Sabitov, B.F. Timershin, E.Yu. Balzamova Increase of efficiency of heat sources work due to application of condensation economizers on an example of a boiler PTVM-180, IOP Conference Series: Materials Science and Engineering, 412, 012007 (2018)

5. G.A. Aminova, G.V. Manuiko, T.V. Ignashina, V.V. Bronskaya, N.E. Kharitonova, G.S. D'Yakonov, V.P Arkhireev Optimal parameters of butadiene polymerization in the synthesis of rubber on a neodymium-containing catalytic system, Theoretical Foundations of Chemical Engineering, 40, pp. 59-67 (2006)

6. G.A. Aminova, M.D. Bronshtejn, G.V. Manujko, T.V. Ignashina, V.V. Davydova, O.V. Antonova, G.S. D'yakonov, I.G. Reshetova, N.E. Kharitonova Method of solution of a system of equations describing the continuous process of polymerization under conditions of a polyaddition reaction., Inzhenerno-Fizicheskii Zhurnal, 75, pp. 165-169 (2002)

7. O.S. Kharitonova, V.V. Bronskaya, T.V. Ignashina, A.A. Al-Muntaser, L.E. Khairullina Modeling of absorption process using neural networks, IOP Conference Series: Earth and Environmental Science, 315, 032025 (2019)

8. Balzamov D S, Akhmetova I G, Balzamova E Yu, Oykina G I and Coman G An analysis of the viability of implementing steam screen machines at the facilities of energy generation enterprises to reduce the energy costs for their own need E3S Web of Conferences 12401016 (2019) 